\title{
ANOMALOUS STRAIN RESPONSE TO RAINFALL IN RELATION TO EARTHQUAKE OCCURRENCE IN THE TOKAI AREA, JAPAN
}

\author{
Tsuneo YAMAUCHI \\ Regional Center for Earthquake Prediction Observation, \\ School of Science, Nagoya University, Nagoya, Japan \\ (Received July 25, 1986; Revised February 4, 1987)
}

\begin{abstract}
The effect of rainfall on crustal strain at the Mikawa Crustal Movement Observatory, central Japan, was studied in detail with a data set from January 1974 through December 1984. Changes in crustal strain caused by rainfall were successfully simulated by a tank model, in which the crustal strain is given as a nonlinear function of precipitation and time. The simulation error was usually less than $10 \%$, but occasionally it became larger. There were anomalies of two kinds: 1 ) a change in spatial distribution of strains in the observation tunnel; and 2) an increase in simulation error for the rainfall effect. These anomalous responses seem to be related to the occurrence of nearby earthquakes within a particular area around the observatory. The logarithmic duration time of anomaly was roughly proportional to the earthquake magnitude. Data from the past eleven years indicate that about $50 \%$ of $M \geq 3.5$ earthquakes in the area were preceded by anomalous strain responses if they occurred after rain. The change in strain response to rainfall at this observatory could be a precursor of a nearby earthquake.
\end{abstract}

\section{Introduction}

Several abnormal crustal movements prior to earthquakes have been reported during long-term continuous observations of tilts and strains. According to KASAHARA (1976), a correlation between crustal strain changes and the water discharge from observation tunnels became obscure at the Erimo Geophysical Observatory, Hokkaido, 3-4 months before the 1973 Nemuro-Hanto-oki earthquake $(M=7.4)$. IsHII (1976) reported that at the Akita Geophysical Observatory, Tohoku, an unusual change of tilt was detected using a Chebychev prediction filter before an $M=6.2$ earthquake at an epicentral distance of $60 \mathrm{~km}$. OIKE and KisHimoto (1976) suggested that movements of a fractured zone of the Yamasaki fault were related to seismic activities in the surrounding area. An abnormal strain change at Kishu Mine before and after the November 1973 earthquake in the Kii Peninsula was reported by Ozawa (1978). Precursory tilt changes at Usami (YANAGISAWA, 1980), at Enzan (SATo et al., 1984), and a strain change at Ikuno (FUIMORI et al., 1984) were interpreted as anomalies observed in and near fractured 
Table 1. List of earthquakes preceded by precursors.

\begin{tabular}{|c|c|c|c|c|c|c|}
\hline Date & Location & $M$ & $D$ & $r$ & $T$ & Reference \\
\hline Oct. 16,1970 & $\begin{array}{l}\text { Southeastern } \\
\text { Akita Prefecture }\end{array}$ & 6.2 & 0 & 80 & 90 & IsHII (1976) \\
\hline June 17,1973 & Off Nemuro Peninsula & 7.4 & 40 & 250 & 60 & KASAHARA (1976) \\
\hline Nov. 25,1973 & $\begin{array}{l}\text { Central Wakayama } \\
\text { Prefecture }\end{array}$ & 5.9 & 60 & 43 & 26 & OzAWA (1978) \\
\hline June 29,1980 & East off Izu Peninsula & 6.7 & 10 & 14 & 8 & YANAGISAWA (1980) \\
\hline Aug. 8,1983 & Kanto-Chubu border & 6.0 & 22 & 31 & 18 & SATO et al. (1984) \\
\hline May 30,1984 & Northern Kinki & 5.6 & 17 & 31 & 6.5 & FUJIMORI et al. (1984) \\
\hline
\end{tabular}

$D$, Depth $(\mathrm{km}) ; r$, epicentral distance $(\mathrm{km}) ; T$, precursor time (day); $M$, magnitude.

zones. The earthquakes following these precursors are summarized in Table 1 .

Generally speaking, however, signals of such kinds are not always obvious due to intense background noise. Among a variety of noise, the greatest is the effect of rainfall. Its elimination is, therefore, most important in the analysis of crustal strain. In this paper, the author investigates the records of crustal strains from January 1974 to December 1984 in order to elucidate the rainfall effect on strain changes at the Mikawa Crustal Movement Observatory, Tokai district, central Japan, which has been operating since 1973 . The factors that constrain the strain response to rainfall are investigated using a tank model and discussed in terms of earthquake occurrence in the area.

\section{Geological Setting and Instrumentation}

The Mikawa Observatory $\left(137^{\circ} 28.2^{\prime} \mathrm{E}, 34^{\circ} 45.6^{\prime} \mathrm{N}\right.$, altitude $\left.67 \mathrm{~m}\right)$, shown by a large closed circle in Fig. 1, is located near two major tectonic lines: 1) the Akaishi Tectonic Line (ATL), striking north-south along the Tenryu River at a distance of $30 \mathrm{~km}$ from the observatory; and 2) the Median Tectonic Line (MTL), the longest tectonic line in Japan, striking northeast-southwest in this area only $10 \mathrm{~km}$ from the observatory. The observation site is located in the Chichibu System of the Jurassic age, which is developed zonally and runs parallel to the MTL. Rock formations in the Chichibu System are characterized by extensive fractured zones and faults (MIZUGAKI, 1985). Seismic activity around the observatory has been markedly high in central Japan (YAMAUCHI, 1985). A horizontal tunnel with two branches in different directions was dug under a hillside behind the observatory to install instruments at depths of more than $40 \mathrm{~m}$ below the surface. Rocks around the observation tunnel, comprised of chert, sandstone, and shale (Fig. 2), were so weak that about three-quarters of the tunnel had to be reinforced with concrete for safety.

Three silica-tube extensometers and two water-tube tiltmeters were installed in the tunnel. These extensometers are referred to as NS, NE, and EW according to their approximate directions (Fig. 3). Extensometer EW is approximately parallel to 


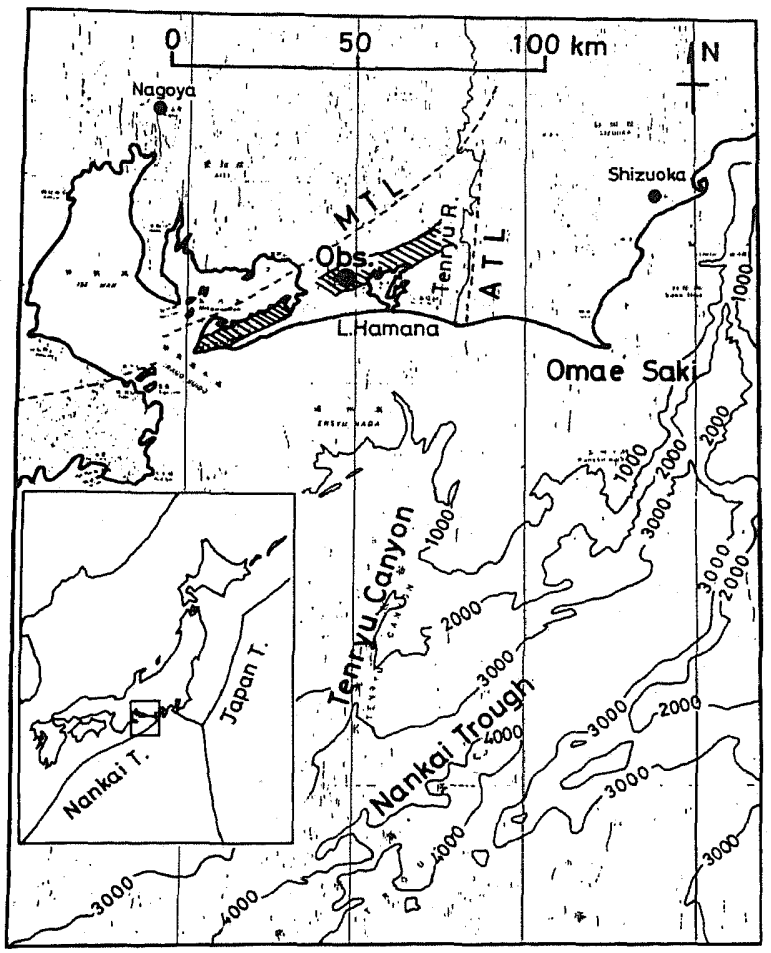

Fig. 1. Map showing locations of the Mikawa Crustal Movement Observatory (large solid circle) and the major geological structures. Hatched zones indicate the portions of Chichibu belt visible on the surface. Dashed lines are the Median Tectonic Line (MTL) and the Akaishi Tectonic Line (ATL).

the geological trend. Each was equipped with two or three detectors for measuring lateral strain changes along each direction. Numbers after the letters NS, NE, and EW denote distances (in meters) between detectors and the fixed ends of the respective extensometers (YAMAUCHI et al., 1974). Detectors and amplifiers show low drift and stability sufficient for long-term observation: The drift and the variation of sensitivity are less than $\pm 2.0 \times 10^{-8}$ strain/yr and $\pm 0.3 \% / \mathrm{yr}$, respectively (YAMAUCHI, 1976). Measurements of atmospheric pressure and precipitation have also been made at the observatory. The longest interruption of recording was only $8 \mathrm{hr}$ since the beginning of observation.

\section{Simulation of Strain Response to Rainfall}

Strain changes in directions $\mathrm{N} 26^{\circ} \mathrm{W}$ (denoted by NS) and $\mathrm{N} 19^{\circ} \mathrm{E}$ (denoted by NE) are shown in Fig. 4, for the period from January 1974 through December 1976. Many impulsive disturbances are recognized on all charts. It is obvious from a 


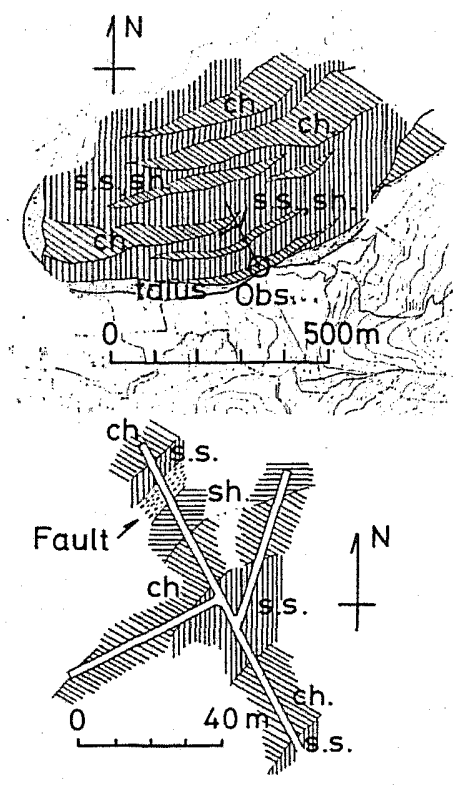

Fig. 2. Geological maps around the observatory (circle) and in the observation tunnel. ch, Chert; s.s, sandstone; sh, shale.

comparison between strain changes and precipitation (bottom figure) that the violent fluctuation of strain is evidently caused by frequent rainfall. It is also recognized that these sharp changes are almost the same in shape. The effect of an impulsive rainfall on strain seems to begin with a contraction immediately after the rainfall, which reaches a maximum within a few days, and then decreases gradually for a few weeks until the contraction disappears. Amplitudes and duration times depend on precipitation. The effect on strain increases as the amount of precipitation increases, although the relation is not linear. When rainfall is light, no change in strain is recognized. In rainy seasons, the effect of one rainfall is apt to overlap that of the previous one, so that the pattern becomes complicated. TANAKA (1979) found that the change of strain with time had a property similar to that of the change of groundwater depth. Based on the tank model, which has commonly been used in the simulation of groundwater flow (SugaWARA, 1973), TANAKA (1979) adopted a two-tank model to analyze the strain changes at Yura Station, Wakayama Prefecture. His results, although not quantitative, provided a reasonable explanation of crustal deformation after rainfall. In the following, the author will develop a proper tank model for the simulation of strain change at the Mikawa Observatory.

The model consists of three subtanks, A, B, and C (Fig. 5). Precipitation $P(t)$ is the input to the top tank (A), which has a capacity limit and three outlets. The tank is assumed to overflow at water level $H_{\mathrm{a} 3}$. The flow from each outlet is assumed to 


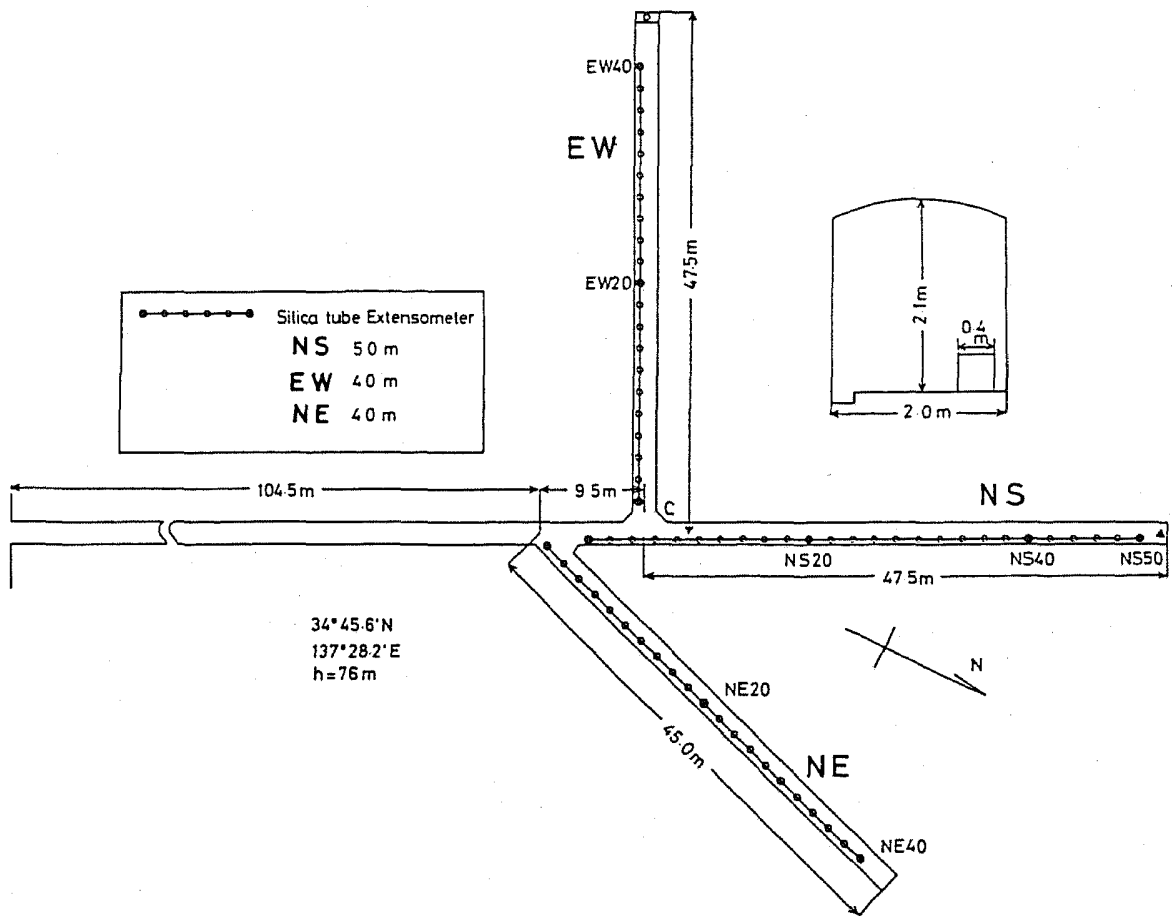

Fig. 3. Arrangement of instruments in the observation tunnel.

be proportional to the height difference between the water level $H_{\mathrm{a}}$, and the outlet $H_{\text {ai }},(i=1,2)$. The rate of water level is expressed as

$$
\mathrm{d} H_{\mathrm{a}} / \mathrm{d} t=P(t)-a_{0} H_{\mathrm{a}}-a_{1}\left(H_{\mathrm{a}}-H_{\mathrm{a} 1}\right)-a_{2}\left(H_{\mathrm{a}}-H_{\mathrm{a} 2}\right)
$$

where

$$
a_{i}= \begin{cases}\text { const. }(\neq 0) & \text { for } H_{\mathrm{a}} \geq H_{\mathrm{a} i}, \\ 0 & \text { for } H_{\mathrm{a}}<H_{\mathrm{a} i},(i=1,2) .\end{cases}
$$

The flow from the second outlet, $O_{\mathrm{a}}(t)$, to the next tank (B) is given by

$$
O_{\mathrm{a}}(t)=\left\{\begin{array}{ll}
a_{1}\left(H_{\mathrm{a}}-H_{\mathrm{a} 1}\right) & \text { for } H_{\mathrm{a}} \geq H_{\mathrm{a} 1} \\
0 & \text { for } H_{\mathrm{a}}<H_{\mathrm{a} 1}
\end{array} .\right.
$$

The water level in tank B may be similarly described as

$$
\mathrm{d} H_{\mathrm{b}} / \mathrm{d} t=O_{\mathrm{a}}(t)-b_{0} H_{\mathrm{b}}-b_{1}\left(H_{\mathrm{b}}-H_{\mathrm{b} 1}\right)-b_{2}\left(H_{\mathrm{b}}-H_{\mathrm{b} 2}\right)
$$

where

$$
b_{i}= \begin{cases}\text { const. }(\neq 0) & \text { for } H_{\mathrm{b}} \geq H_{\mathrm{b} i} \\ 0 & \text { for } H_{\mathrm{b}}<H_{\mathrm{b} i},(i=1,2) .\end{cases}
$$




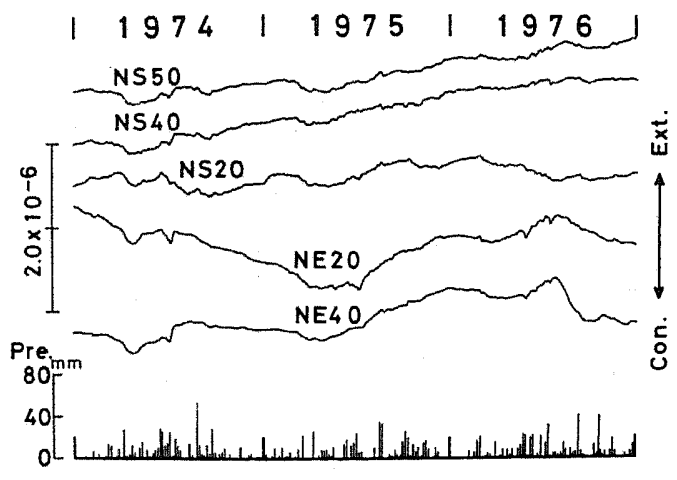

Fig. 4. Secular strain changes measured on extensometers NS and NE during the first three years from January 1974. Precipitation averaged for every 5 days is given on the bottom. The notations of curves indicate the locations of the detectors shown in Fig. 3.

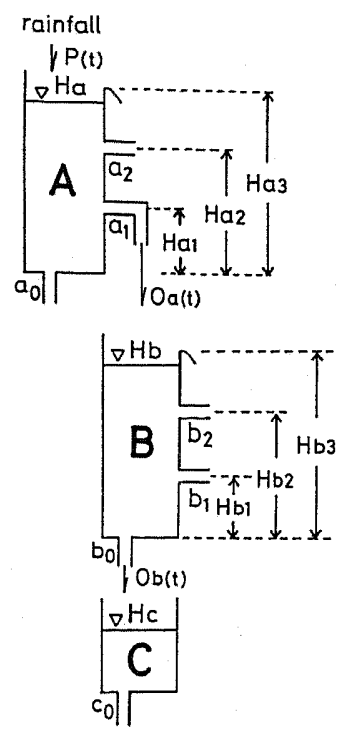

Fig. 5. A tank model for simulation of strain response to rainfall.

The flow from the bottom outlet, $O_{\mathrm{b}}(t)$, is fed into the last tank $(\mathrm{C})$ which has a single outlet on the bottom

$$
\begin{aligned}
& O_{\mathrm{b}}(t)=b_{0} H_{\mathrm{b}} \\
& \mathrm{d} H_{\mathrm{c}} / \mathrm{d} t=O_{\mathrm{b}}(t)-c_{0} H_{\mathrm{c}} .
\end{aligned}
$$

The observed strain change, $S$, is assumed to be proportional to the water level $H_{\mathrm{c}}$ in tank C 


$$
S=r H_{\mathrm{c}}
$$

where $r=$ const.

Equations (1) to (6) are numerically solved with a time step of $4 \mathrm{hr}$. The precipitation every $4 \mathrm{hr}$ is interpolated from data given twice a day. The parameters of the model that give the best fit to the observed data during the three years from January 1974 through December 1976 are determined by the method of trial and error, and are listed in Table 2.

The strain change simulated from precipitation showed a small, systematic deviation from the observed one. The output of the model in summer seems somewhat larger than the observed strain. Considering the effect of evapotranspiration of rainwater in summer, a reduction factor is introduced for precipitation in July, and August. A factor of 0.9 seems to give the best fit to observations.

Examples of simulation of the strain changes in extensometers NS and NE are shown in Figs. 6 and 7. The rain effect is assumed to be the same for both directions. Differences between the simulation and the observations are also plotted against time together with semi-diurnal precipitation. The simulation agrees well with observations not only at NS40 and NE40 but also at other detectors. Small fluctuations in observed strain-curves are caused by the tidal force, which is not taken into account in the present study. Figure 8 illustrates a comparison between strains measured at $20-\mathrm{m}$ and $40-\mathrm{m}$ spans for the period from September 22 through October 7, 1974. The graph on the bottom indicates semi-diurnal precipitation. The top is the output from the simulator. Strains measured at various places and their differences are shown in between. The differences between the two measurements on the same extensometer are as small as $10^{-8}$, about one order of magnitude less than the strain variation itself. The remarkable resemblance among these curves implies a uniform deformation of rock at the observation site.

Once the parameters have been determined, it is easy to predict crustal deformation due to rainfall. Curves in Fig. 9 show the strains after the elimination of rainfall effects from the observed strain curves in Fig. 4. It is possible to eliminate about $90 \%$ of the effects of rainfall during the whole period from January 1974 through December 1984 using the parameters determined with data from the first three-year period.

Table 2. Parameters of tank model.

\begin{tabular}{|c|c|c|c|c|c|}
\hline \multicolumn{2}{|c|}{ Tank A } & \multicolumn{2}{|c|}{ Tank B } & \multicolumn{2}{|r|}{ Tank C } \\
\hline$H_{\mathrm{a} 1}$ & $10 \mathrm{~mm}$ & $H_{\mathrm{b} 1}$ & $16 \mathrm{~mm}$ & & \\
\hline$H_{\mathrm{a} 2}$ & $25 \mathrm{~mm}$ & $H_{\mathrm{b} 2}$ & $30 \mathrm{~mm}$ & $r$ & $4.55\left(10^{-8} / \mathrm{mm}\right)$ \\
\hline$H_{\mathrm{a} 3}$ & $120 \mathrm{~mm}$ & $H_{\mathrm{b} 3}$ & $50 \mathrm{~mm}$ & & \\
\hline$a_{0}$ & 0.36 & $b_{0}$ & 0.105 & & \\
\hline$a_{1}$ & 0.15 & $b_{1}$ & 0.045 & $C_{0}$ & 0.020 \\
\hline$a_{2}$ & 0.10 & $b_{2}$ & 0.10 & & \\
\hline
\end{tabular}




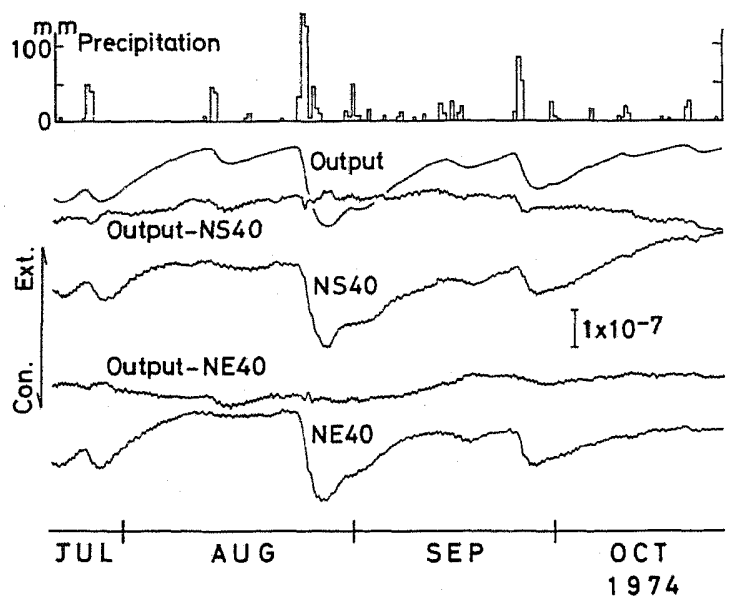

Fig. 6. Output from the tank model compared with strain changes at NS40 and NE40 in the period from July 20 to October 27, 1974. Precipitation every $12 \mathrm{hr}$ is given on the top figure.

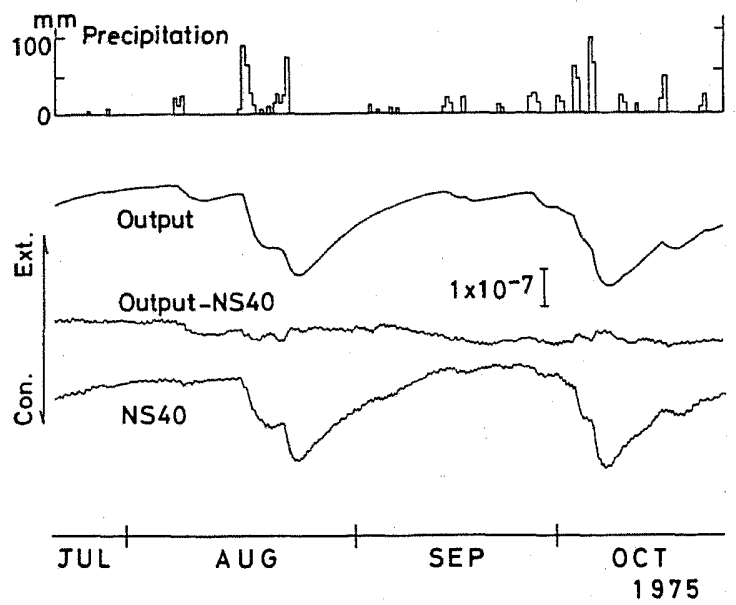

Fig. 7. Output from the tank model compared with the strain change at NS40 in 1975. Notations are the same as in Fig. 6.

\section{Anomalous Effects of Rainfall}

The ground deformation caused by rainfall can be successfully calculated using a tank model without much difficulty. However, conspicuous discrepancies between the model and the observation are occasionally found. Such discrepancies seem to appear before the occurrence of nearby earthquakes. In some cases of large earthquakes, the discrepancies continued long even after the events. Figure 10 illustrates the strain response to rainfall and the output of the model before and 


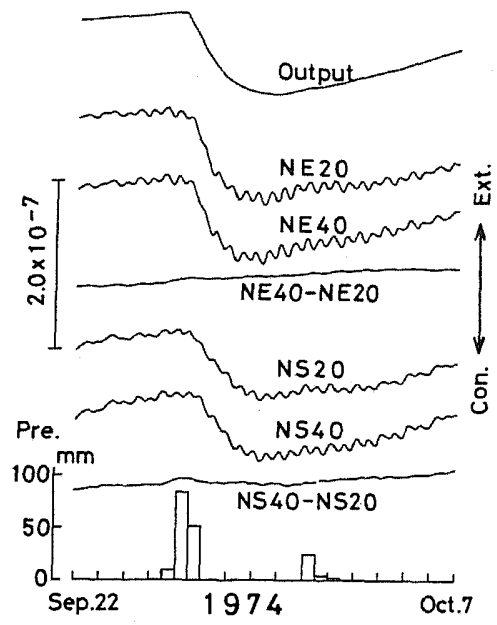

Fig. 8. Strain recoveries after rainfall observed on extensometers NS and NE. These strain-curves are similar in shape and can be simulated by the tank model with the parameters in Table 2 as shown by the top curve. Pre. indicates semi-diurnal precipitation.

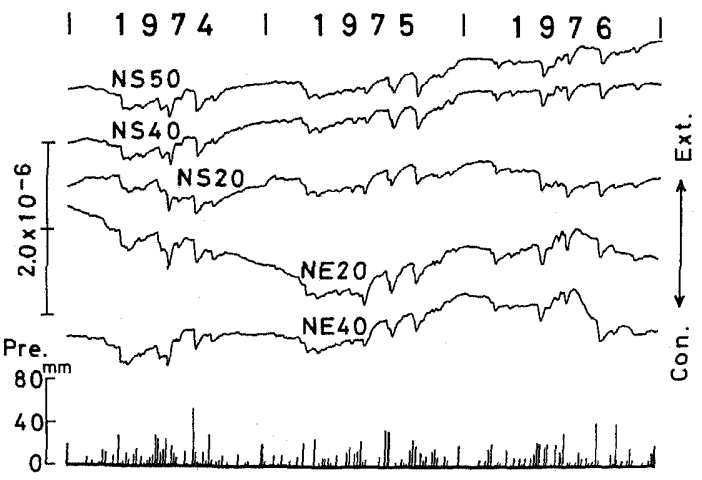

Fig. 9. Secular strain changes on extensometers NS and NE corrected for rainfall effects and the precipitation during the same period as in Fig. 4. The notations are the same as in Fig. 4.

after the earthquake at the Aichi-Gifu border in March $1975(M=5.3$, epicentral distance $=85 \mathrm{~km}$, depth $=50 \mathrm{~km}$ ). The bottom figure indicates semi-diurnal precipitation. The observed contractions on the NS and on the NE strain-curves were not only more pronounced than those expected from rainfall, but also continued after the earthquake. In order to make this clear, data from about three months including the event are illustrated in Fig. 11. The difference between the simulation and the observation is also shown in this figure. It seems that a sudden 


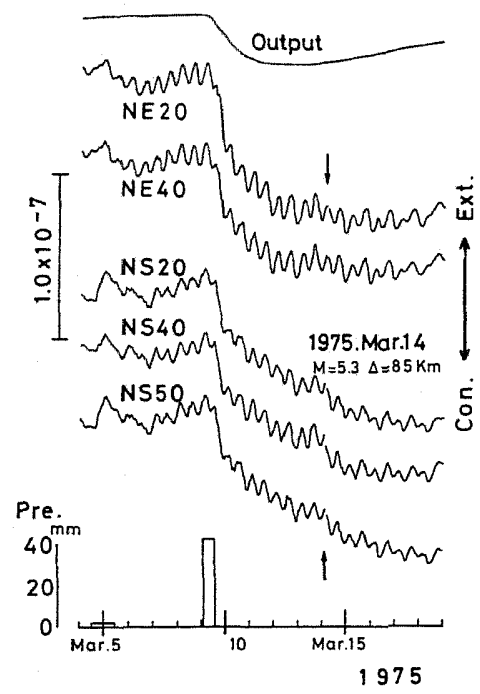

Fig. 10. Anomalous strain response to rainfall on extensometers NS and NE before and after the earthquake on March 14, $1975(M=5.3)$. Arrows indicate the time of earthquake occurrence.

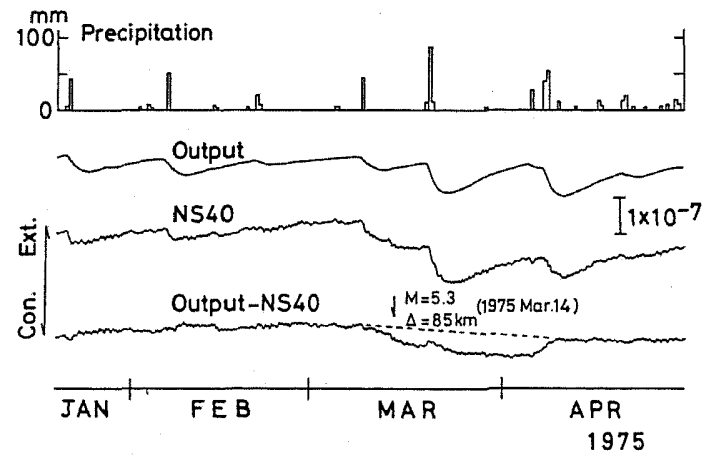

Fig. 11. Change of strain response to rainfall at NS40 from January 11 to April 20, 1975. The anomaly obviously continued from March until April.

deflection of the curve started 15 days before the event and continued for about one month.

In the case of the earthquake on November $12,1975(M=4.2) 9 \mathrm{~km}$ from the observatory, the strain difference between NS40 and NS20 showed a sudden deflection from its general trend on November 9, 1975 (Fig. 12). This observation suggests that the response to rainfall at the observation site was not uniform in space. Figure 13 shows another example of a marked dissimilarity between strains at NE40 and NE20. The difference between the two showed noticeable deviations 


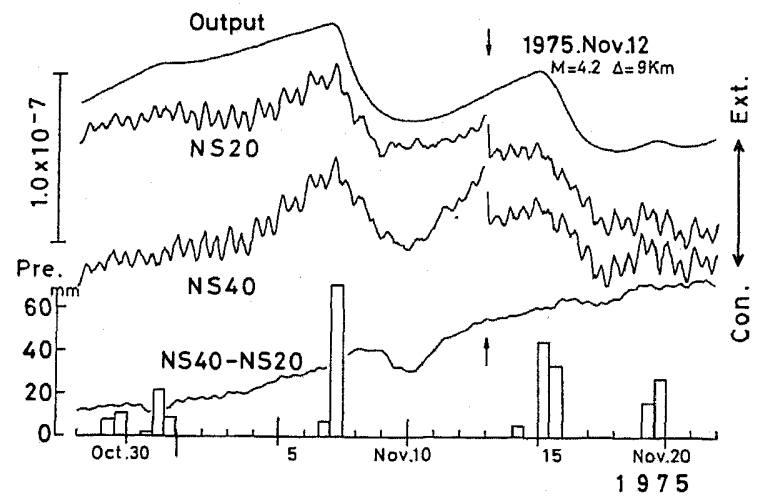

Fig. 12. Anomalous strain response to rainfall on extensometer NS before the earthquake on November 12, 1975.

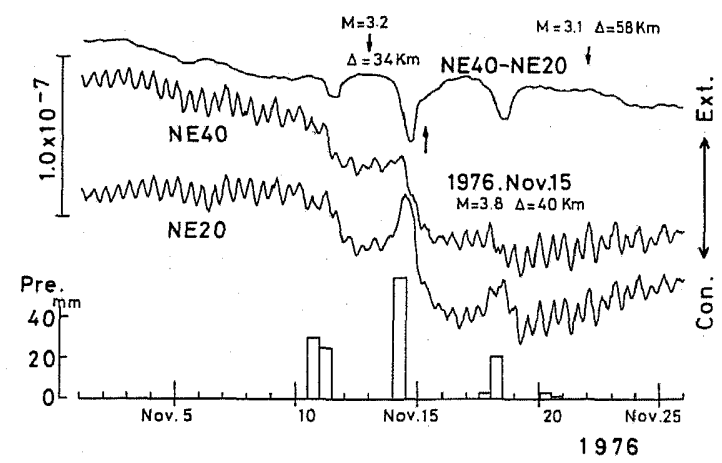

Fig. 13. Anomalous strain response to rainfall on extensometer NE before and after the earthquake on November 15, 1976.

from the general trend three times. The largest one appeared one day before the event of November 15, $1976(M=3.8)$. There were two other similar but minor fluctuations and two small nearby events within two weeks. This kind of change is sometimes observed for earthquakes near the observatory.

Considering the pattern of variation and the amplitude of deformation, the anomalous cases are defined as follows:

Type A: the discrepancy between simulation and observation exceeds $30 \%$ of the simulated response.

Type B: a strain difference between two detectors on the same extensometer exceeds $2.0 \times 10^{-8}$.

In this paper, disturbances with duration times shorter than $12 \mathrm{hr}$ or those for precipitation of less than $15 \mathrm{~mm}$ were not considered, because they were too small to be judged as abnormal phenomena. 


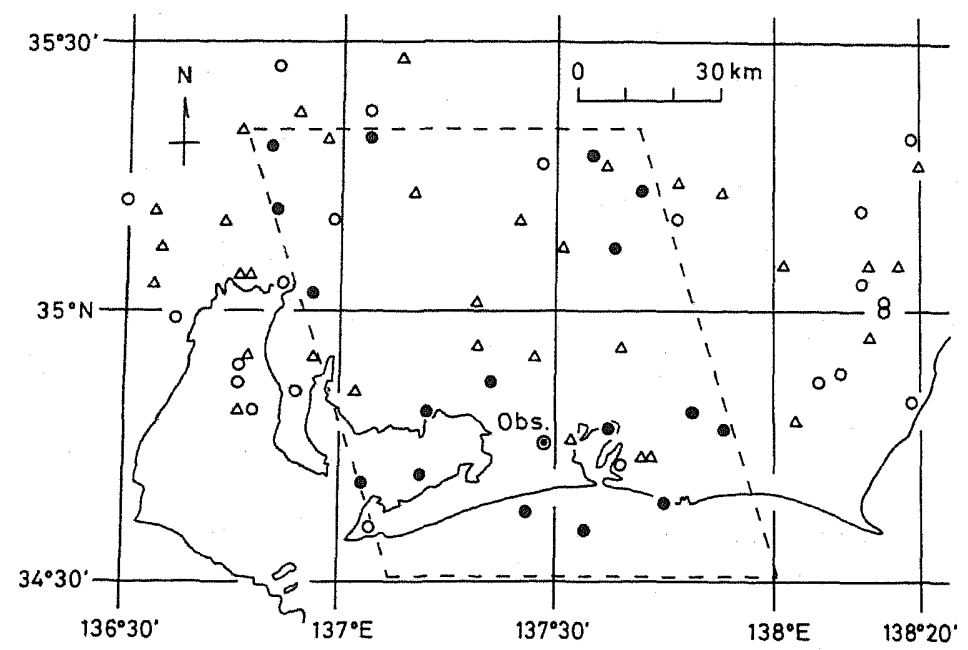

Fig. 14. Epicenters located by JMA for $M \geq 3.5$ earthquakes near the observatory in the period from January 1974 to December 1984. Closed circles, event preceded by precursor; open circles, event not preceded by any precursor; triangle, event at no rainfall or at precipitation of less than $15 \mathrm{~mm}$.

\section{Distribution of Earthquakes Associated with Abnormal Responses to Rainfall}

The simultaneous occurrence of an abnormal strain change and a nearby earthquake was statistically examined to determine whether it represents some relation between the two, or whether it is merely attributed to chance. Figure 14 shows the epicentral distribution of the $M \geq 3.5$ events that occurred in the region bounded by longitudes $136^{\circ} 30^{\prime} \mathrm{E}$ and $138^{\circ} 20^{\prime} \mathrm{E}$ and latitudes $34^{\circ} 30^{\prime} \mathrm{N}$ and $35^{\circ} 30^{\prime} \mathrm{N}$ in the period from January 1974 through December 1984. Seventeen earthquakes were recognized as associated with abnormal response to rainfall. They are plotted by closed circles in Fig. 14, and are also listed in Table 3. Open circles denote the events that occurred after rainfall but when the responses to rainfall were normal, while triangles denote events at times of insufficient or no precipitation. The distribution of closed circles is never random; all the closed circles were confined in a region bounded by the quadrangle shown in the figure. Roughly speaking, about $50 \%$ of the $M \geq 3.5$ events in this block were accompanied by abnormal strain response to rainfall if they occurred after rainfall. There were only three cases in which abnormal strain responses were obviously observed, but no earthquake followed. On July 7, 1974, there was a heavy rain of $295 \mathrm{~mm}$ within one day. The strain changes at NS40 and NS50 were delayed $12 \mathrm{hr}$ compared to the simulation, but those at NS20 were not. Hence, a discrepancy defined as Type B was recognized on extensometer NS after the rain, but there was no earthquake. There was a similar case in August 1982. The third case occurred in January 1980 after a light rain. These are listed in Table 4. When small earthquakes $(M<3.5)$ occurred in the 
immediate vicinity of the observatory, some of them were preceded by abnormal strain changes, as shown in Table 5.

\section{Discussion}

There have been several reports on the relation between rainfall and earthquake occurrence. TANAKA (1979), discussing the effect of rainfall on tilt movements at Yura station, suggested that through the behavior of underground water, the rainfall effect is indirectly controlled by temporary change in the crustal stress field. OzAWA (1969) reported that the response of crustal deformation to a heavy thunderstorm at the Osakayama Crustal Movement Observatory, Shiga Prefecture, was abnormal prior to the occurrence of a magnitude 5.6 event near the observatory. According to OIKE (1977), microearthquake activity along the Yamasaki fault, an active fault in southwest Japan, became high when a large effect of rainfall was observed on strain records. These observations are, in a sense, regarded as similar to those presented in this paper.

Considering that the abnormal strain response to rainfall is a sort of earthquake precursor, the present author defines the precursor time as the time interval between the initiation of an anomalous response and earthquake occurrence. According to RIKITAKE (1979), the relation between the precursor time, $T$, and the earthquake magnitude, $M$, is statistically represented by $\log T=0.60$ $\times M-1.01$, where $T$ is measured in units of days. In order to find a similar relationship, logarithmic precursor times defined as above are plotted against

Table 3. List of earthquakes preceded by precursors $(M \geq 3.5)$.

\begin{tabular}{llrrrr}
\multicolumn{1}{c}{ Date } & \multicolumn{1}{c}{ Location } & $M$ & $D$ & $r$ & $T$ \\
\hline Feb. 10,1974 & Western Aichi Prefecture & 5.3 & 40 & 60 & 6.0 \\
Feb. 24, 1974 & Western Shizuoka Prefecture & 4.6 & 0 & 37 & 4.5 \\
Mar. 14, 1975 & Aichi-Gifu border & 5.3 & 50 & 85 & 15 \\
Nov. 12, 1975 & South coast of Aichi Prefecture & 4.2 & 29 & 9 & 6.0 \\
May 9,1976 & South off Shizuoka Prefecture & 4.1 & 40 & 19 & 8.0 \\
June 6,1976 & Nagano-Aichi border & 4.0 & 10 & 55 & 5.0 \\
Nov. 15, 1976 & Eastern Aichi Prefecture & 3.8 & 50 & 40 & 1.5 \\
Dec. 27, 1976 & Near Hamamatsu & 3.5 & 40 & 27 & 2.5 \\
Apr. 30,1977 & Western Shizuoka Prefecture & 4.2 & 20 & 30 & 7.0 \\
July 19,1977 & Southern Aichi Prefecture & 3.5 & 40 & 26 & 3.5 \\
Aug. 6, 1977 & Western Aichi Prefecture & 4.3 & 50 & 73 & 5.0 \\
May 26, 1979 & Aichi-Gifu border & 3.7 & 40 & 73 & 17 \\
Mar. 4, 1980 & Southern Chubu & 3.5 & 40 & 16 & 7.0 \\
Aug. 18,1981 & Southern Chubu & 5.0 & 50 & 59 & 16 \\
June 21, 1982 & South coast of Chubu & 4.9 & 40 & 39 & 21 \\
Mar. 16, 1983 & South coast of Chubu & 5.7 & 40 & 14 & 21 \\
Mar. 26, 1983 & South coast of Chubu & 3.5 & 42 & 25 & 3.0 \\
\hline
\end{tabular}

$D$, Depth $(\mathrm{km}) ; r$, epicentral distance $(\mathrm{km}) ; T$, precursor time (day); $M$, magnitude, 
Table 4. List of abnormal strain responses to rainfall not related to earthquake occurrence.

\begin{tabular}{cccc}
\hline Date & Component & Type & Precipitation \\
\hline July 7, 1974 & NS & B & $295 \mathrm{~mm}$ \\
Jan. 13, 1980 & NS & B & $20 \mathrm{~mm}$ \\
Aug. 1, 1982 & NS & B & $304 \mathrm{~mm}$ \\
\hline
\end{tabular}

Table 5. List of earthquakes preceded by precursors $(M<3.5)$ at the Mikawa Observatory.

\begin{tabular}{llrrrr}
\multicolumn{1}{c}{ Date } & \multicolumn{1}{c}{ Location } & $M$ & $D$ & $r$ & $T$ \\
\hline Oct. 12, 1976 & South off Shizuoka Prefecture & 3.2 & 40 & 19 & 1.5 \\
Oct. 24, 1976 & Off Atsumi Peninsula & 3.0 & 30 & 47 & 1.0 \\
Oct. 28, 1976 & Southern Aichi Prefecture & 2.6 & 0 & 9 & 0.5 \\
Nov. 12, 1976 & South off Shizuoka Prefecture & 3.2 & 30 & 34 & 1.5 \\
Nov. 22, 1976 & Western Shizuoka Prefecture & 3.4 & 60 & 55 & 4.5 \\
Aug. 2, 1977 & Eastern Aichi Prefecture & 3.0 & 40 & 18 & 1.5 \\
Mar. 3,1980 & Southern Chubu & 3.4 & 40 & 21 & 6.0 \\
\hline
\end{tabular}

$D$, Depth $(\mathrm{km}) ; r$, distance $(\mathrm{km}) ; T$, precursor time (day); $M$, magnitude.

magnitudes with closed circles in Fig. 15. Since the magnitude range of $3.5 \leq M \leq 5.7$ in Table 3 is too small to discuss the relation between $T$ and $M$, the data listed in Tables 1 (open circles) and 5 (closed circles for $M<3.5$ ) are also included. It is not possible to observe precursory changes during insufficient rainfall. Therefore each closed circle in Fig. 15 may give a short precursor time, but interval between rainfalls is not so long as to require further corrections. The data in Table 1 were plotted on the extension of the present data set. A dashed line, $\log T=0.34$ $\times M-0.72$, is obtained by the least squares method, which gives less dependence on magnitude than does Rikitake's formula for the magnitude range in question.

AOKI et al. (1984), investigating the geometrical shape of the Philippine Sea plate subducting from the Suruga and Nankai troughs, west of the Izu Peninsula, concluded that a seismically active belt extending northwestward from Lake Hamana should have been subjected to a tensile stress. YAMAZAKI and OOIDA (1985) pointed out from a microearthquake study that the Philippine Sea plate is subducting with disruption beneath the southern coastal region of central Japan. They divided the subducting plate into the Suruga, Tokai, and Tonankai slabs (Fig. 16). YAMAUCHI (1985) investigated the activity of the $M \geq 5.0$ earthquakes in the coastal region of central Japan in the past 100 years and found that seismic activity around Lake Hamana has been very high. The majority of the events that were preceded by abnormal strain responses were deeper than $20 \mathrm{~km}$, that is, these earthquakes occurred within the subducting zone. The distribution of the events was confined to the Tokai slab in Fig. 16. When a tectonic stress relating to earthquake generation is applied to this slab, stress concentrations may take place 


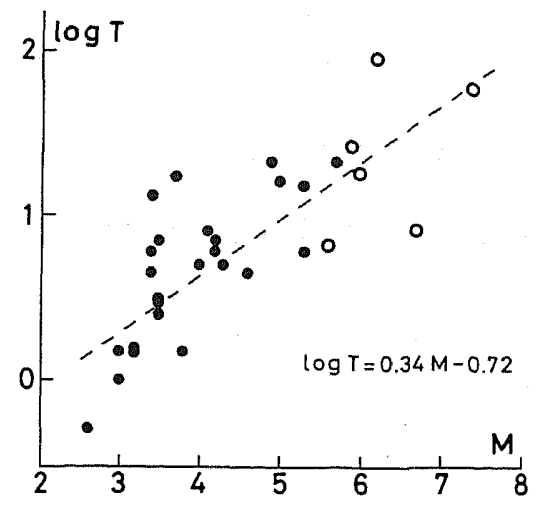

Fig. 15. Plots of logarithms of precursor times $T$ (in days), against earthquake magnitude $M$. The gradient of the dashed line obtained by least squares fitting is smaller than that in Rikitake's $M-T$ relation. Closed circles are the data obtained in this study, and open circles are those listed in Table 1.

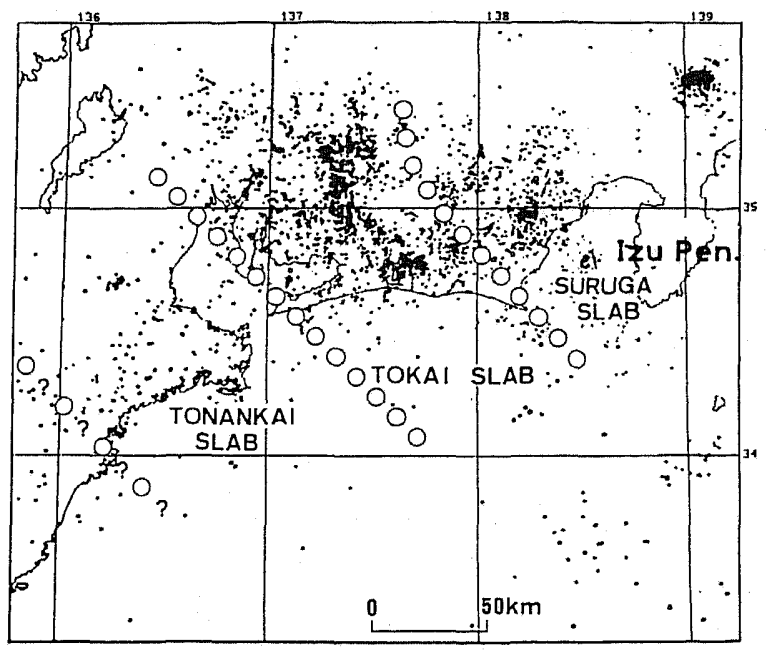

Fig. 16. Distribution of earthquakes between $20 \mathrm{~km}$ to $80 \mathrm{~km}$ in depth for the period from April 1978 through March 1984. Boundaries of descending slabs are shown by open circles (after YAMAZAKI and OOIDA, 1985).

not only at the seismic source region, but also at some places along the boundary of crustal blocks near the surface. Considering the complex geological features in central Japan, the author infers that the observation site is one such place.

Some earthquakes are believed to be preceded by changes in the physical properties of the crust. In this context, Mirumo et al. (1977) reported an amplitude change of tidal strains at two observatories at Kamitakara and Inuyama prior to the 1969 central Gifu earthquake $(M=6.6)$. They inferred that the change in crustal 
properties would have taken place in the source region. Similarly, if the permeability of underground water in rock is controlled by a stress concentration, the flow of underground water may be disturbed. The change in flow pattern is directly related to the change in response function. The spatial extent of the flow pattern may be various: If the change extends all over the tunnel, a Type A anomaly is expected, otherwise, Type B is expected. The present author believes that rainfall is useful for detecting some kinds of changes in the crustal properties sensitive to earthquake occurrence.

The above mechanism is one possible model of anomalous response, although it cannot detect the precursory strain when no rain falls.

\section{Conclusions}

Long-term observation of crustal strains at the Mikawa Observatory suggests that the changes in strain due to rainfall can be evaluated from the time-series of precipitation. The author has adopted a tank model to simulate the strain response to rainfall. The model parameters, determined with a three-year data set, are equally applicable to the other eight years in the observation period. The error of simulation is usually less than $10 \%$, except in unusual cases.

The occurrence of unusual strain behavior due to rainfall was studied in detail, with special reference to earthquake prediction. The observational results obtained in the present study are as follows:

(1) Conspicuous anomalies of strain responses to rainfall occasionally appear before $M \geq 3.5$ earthquakes near the observatory. More than 17 cases were found on the strain records from 1974 to 1984 . They are classified into two types: (i) a large simulation error for the rainfall effect; and (ii) irregular responses in the observation tunnel.

(2) The earthquakes that were preceded by abnormal strain changes were mostly confined within the Tokai slab, a part of the subducting Philippine Sea plate.

(3) The linear relationship between the logarithm of precursor time $T$ (in days), and earthquake magnitude, $M$, is given by $\log T=0.34 M-0.72$.

The author infers that these anomalies were controlled by the change in permeability of underground water beneath the observatory. The Chichibu System, where the observations were conducted, is geologically known as a large-scale fractured zone in central Japan. Such a zone might be sensitive to the stress change related to the earthquake generating force. A local concentration of stress, if it occurs at the observatory, is perhaps a favorable condition to generate a precursory phenomenon even for a small earthquake. Although, it is not yet possible to detect any earthquake precursor during periods of no rain, the abnormal response to rainfall is regarded as a type of earthquake precursor.

The author would like to express his sincere gratitude to Professor Harumi Aoki for many helpful discussions and for his critical reading of the manuscript. He also thanks $\mathrm{Mr}$. 
Mamoru Yamada and Mr. Takashi Okuda of Nagoya University for their able assistance at the Mikawa Crustal Movement Observatory.

\section{REFERENCES}

Aoki, H., F. YAmaZaki, and T. OOIDa, Subduction of Philippine Sea plate at Suruga trough, Prog. Abstr. Seismol. Soc. Jpn., 38, 1984 (in Japanese).

FUJimORI, K., T. TABEI, and Y. TANAKA, Continuous observation of crustal movements at Ikuno before and after the earthquake of May 30, 1984, Prog. Abstr. Seismol. Soc. Jpn., 9, 1984 (in Japanese).

IsHII, H., Application of prediction method for analysis of crustal movement, J. Geod. Soc. Jpn., 22, 299-301, 1976.

Kasahara, M., Premonitory crustal movement observed at Erimo before the Earthquake off the Nemuro Peninsula on June 17, 1973, Rep. Symp. Earthq. Predict., 3-14, 1976 (in Japanese with English abstract).

Mikumo, T., M. Kato, H. Doi, Y. Wada, T. Tanaka, R. Shichi, and A. Yamamoto, Possibility of temporal variations in earth tidal strain amplitudes associated with major earthquakes, J. Phys. Earth, 25, Suppl., 123-136, 1977.

MizUGaKI, K., Radiolarian fossils from the Chichibu System, northwest of Hamana Lake, central Japan, Bull. Mizumami Fossil Mus., 12, 171-181, 1985 (in Japanese with English abstract).

OIKE, K., Seismic activities and crustal movements at the Yamasaki fault and surrounding regions in the southwest Japan, J. Phys. Earth, 25, Suppl., 31-41, 1977.

OIKE, K. and Y. KISHImoto, The Yamasaki fault as a test-field for the earthquake prediction, Rep. Symp. Earthq. Predict., 83-90, 1976 (in Japanese with English abstract).

OzaWA, I., Observations of crustal deformations in the periods of the earthquakes at Kamiwachi and Kyoto City, Annu. Disas. Prev. Res. Inst. Kyoto Univ., 12A, 123-136, 1969 (in Japanese with English abstract).

Ozawa, I., Observation of the crustal movement at Kishu Mine-observation by using extensometers, Annu. Disas. Prev. Res. Inst. Kyoto Univ., 21B, 113-117, 1978 (in Japanese with English abstract).

RIKITaKe, T., Classification of earthquake precursors, Tectonophysics, 54, 293-309, 1979.

Sato, H., M. Tatsukawa, and T. OhKubo, Anomalous tilt change preceding the Eastern Yamanashi Earthquake of August 8, 1983, Zisin (J. Seismol. Soc. Jpn.), Ser. 2, 37, 197205, 1984 (in Japanese with English abstract).

Sugawara, M., Ryushutsu Kaiseki-Ho, 2nd Edition, Kyoritsu-Shuppan, Tokyo, 1973 (in Japanese).

TANAKA, T., Effects of rainfalls on tiltmetric and extensometric records and their simulation, J. Geod. Soc. Jpn., 25, 91-100, 1979 (in Japanese with English abstract).

YAMAUCHI, T., On the stability of electronic circuits for strain and tilt meters, J. Geod. Soc. Jpn., 22, 295-296, 1976.

YAMAUCHI, T., Migration of earthquakes $(5.0 \leq M)$ in the southern part of central Honshu, Japan, Zisin (J. Seismol. Soc. Jpn.), Ser. 2, 38, 447-455, 1985 (in Japanese with English abstract).

YAMAUCHI, T., M. YAmadA, and H. AokI, On the observation of crustal deformation at Toyohashi, central Japan (1st report), J. Geod. Soc. Jpn., 20, 45-56, 1974 (in Japanese with English abstract). 
YamaZaKI, F. and T. OoIDA, Configuration of subducted Philippine Sea plate beneath the Chubu district, central Japan, Zisin (J. Seismol. Soc. Jpn.), Ser. 2, 38, 193-201, 1985 (in Japanese with English abstract).

Yanagisawa, M., Rainfall effect on the tilt observations at Usami, the Izu Peninsula, $J$. Geod. Soc. Jpn., 26, 187-199, 1980 (in Japanese with English abstract). 